\title{
Polycyclic Aromatic Hydrocarbons in Surface Water from Wuhai and Lingwu Sections of the Yellow River: Concentrations, Sources, and Ecological Risk
}

\author{
Yun Liu $\left(\mathbb{D}\right.$, Qingwei Bu $\left(\mathbb{D}\right.$, Hongmei Cao $\mathbb{D}^{D}$, Handan Zhang $\mathbb{D}^{D}$, Chuansheng Liu $(\mathbb{D}$, \\ Xiaofan $\mathrm{He}(\mathbb{D}$, and Mengqi Yun (10) \\ School of Chemical \& Environmental Engineering, China University of Mining \& Technology-Beijing, Beijing 100083, China \\ Correspondence should be addressed to Qingwei Bu; qingwei.bu@cumtb.edu.cn
}

Received 27 December 2019; Accepted 5 February 2020; Published 28 February 2020

Guest Editor: Chenglian Feng

Copyright ( 92020 Yun Liu et al. This is an open access article distributed under the Creative Commons Attribution License, which permits unrestricted use, distribution, and reproduction in any medium, provided the original work is properly cited.

\begin{abstract}
In this study, concentrations, sources, and ecological risk of 16 polycyclic aromatic hydrocarbons (PAHs) in 41 surface water samples collected from Wuhai and Lingwu sections of the Yellow River were investigated. The results showed that total PAH concentrations varied from $27.5 \mathrm{ng} / \mathrm{L}$ to $234 \mathrm{ng} / \mathrm{L}$ and from $135 \mathrm{ng} / \mathrm{L}$ to $265 \mathrm{ng} / \mathrm{L}$ in surface water of Wuhai and Lingwu sections, respectively. Source identification was performed by using principal component and multiple linear regression analysis. PAHs in Wuhai section of the Yellow River were mainly from coal combustion (35\%) and vehicle exhausts (34\%). Ecological risk of PAHs to aquatic organisms was assessed by applying the probabilistic risk assessment method. The results showed that the probabilities of exceeding the chronic toxicity for $5 \%$ of the species were $28 \%$ and $32 \%$ for PAHs in surface water from Wuhai and Lingwu sections, respectively. It has been demonstrated that there is an urgent need for environmental managers to take measures to reduce the ecological risk of PAHs in the aquatic environment in both Wuhai and Lingwu sections of the Yellow River.
\end{abstract}

\section{Introduction}

Polycyclic aromatic hydrocarbons (PAHs) are compounds consisting of two or more fused rings that have raised more concerns due to their persistent property and toxicity featured by considerably high direct-acting mutagenicity and carcinogenicity [1]. PAHs find their way into the environment through natural sources such as volcanoes, forest fire, and biosynthetic process. It could also be emitted from diverse anthropogenic sources such as vehicle exhausts; power plants; chemical, coke, and oil-shale industries; and urban sewage $[2,3]$.

It has been demonstrated that, in the process of coal mining, the treatment and storage of coal provided the basic conditions for the release of PAHs into the environment [4-9]. For example, PAHs in coal and coal waste could be leached into the mine water [10] and then enter into the aquatic environment with the discharge of mine water [11]. Therefore, the occurrence of PAHs in surface water nearby the coal mining area has attracted lots of attention recently $[5,9,12,13]$. However, studies on concentrations, sources, and ecological risk of PAHs in surface water of rivers located in or nearby the coal mining area are generally limited at present. Seopela et al. [9] investigated the occurrence levels and evaluated the risk of PAHs in the Loskop Dam nearby the coalmine in South Africa. They reported that the total $\mathrm{PAH}$ concentrations varied from $1170 \mathrm{ng} / \mathrm{L}$ to $14500 \mathrm{ng} / \mathrm{L}$, and it was found that the occurrence of PAHs in the sediment of Loskop Dam could lead to a delay of the development and malformation of zebrafish embryo [9]. Hao et al. [12] investigated the concentrations and sources of PAHs in surface water of Fuyang River nearby the Fengfeng coal mining area. Huang et al. [5] reported that the average concentration of 16 PAHs was $427 \mathrm{ng} / \mathrm{L}$ in surface water of rivers located in Heshan coal district in Guangxi.

In the present study, we aimed to investigate the concentrations, sources, and ecological risk of PAHs in surface water of Wuhai and Lingwu sections of the Yellow River in 
China. Both Wuhai and Lingwu are large coal mining bases in the northwestern China and have a long history of coal mining. Over the years, the coal mining areas in both cities have dramatically expanded. A large number of cultivated land, forest, and grassland have been occupied due to mining activities, resulting in the sharp deterioration of the local ecological environment. The Yellow River is the only surface water resource flowing through Lingwu and Wuhai. During recent years, the water resource of the Yellow River is becoming more and more stressing due to the intensive mining activities, which could also aggravate the degradation of the vulnerable ecosystem.

Therefore, we carried out a field campaign to (i) determine concentrations of PAHs in surface water collected from Wuhai and Lingwu sections of the Yellow River, (ii) identify major sources and origins of PAHs, and (iii) assess the ecological risk of PAHs to aquatic organisms by applying the probabilistic ecological risk assessment. This study would be helpful to the control of PAH risk in rivers located in or nearby coal mining areas.

\section{Materials and Methods}

2.1. Chemicals. The PAH mixture standard was purchased from Accustandard (USA), including naphthalene (Nap), acenaphthylene (Acy), acenaphthene (Ace), fluorene (Flu), phenanthrene (Phe), anthracene (Ant), fluoranthene (Flua), pyrene (Pyr), benzo(a)anthracene (BaA), chrysene (Chr), benzo(b)fluoranthene (BbF), benzo(k)fluoranthene $(\mathrm{BkF})$, dibenzo(a, h)anthracene (DBA), benzo(a)pyrene $(\mathrm{BaP})$, indeno(1,2,3-cd)pyrene (Ind), and benzo(g, h, i) perylene (BghiP). The injection standard (hexamethylbenzene, HMB) was provided by Dr. Ehrenstorfer (Germany). Phe-d10 and Chr-d12 were used as recovery standards and obtained from Accustandard (USA). All solvents, including methanol, dichloromethane, and $n$ hexane, were of HPLC grade and obtained from Fisher (USA). C18 cartridges $(500 \mathrm{mg} / 6 \mathrm{cc}$ ) used for solid phase extraction (SPE) were purchased from Waters (USA).

2.2. Sample Collection and Analytical Procedure. A total of 30 sampling sites at Wuhai section were set up along the mainstream of the Yellow River, while 11 sampling sites were selected at Lingwu section (Figure 1). At each sampling site, approximately four liters of surface water were collected and transported to the lab immediately. All water samples were stored at $4^{\circ} \mathrm{C}$ and analyzed in $24 \mathrm{~h}$. The sampling events were conducted in July, 2019.

The sample pretreatment method for surface water was adapted from $\mathrm{Bu}$ et al. [14]. In brief, approximately $2 \mathrm{~L}$ surface water samples (in triplicate) were filtered using a glass fiber filter $(0.45 \mu \mathrm{m}$, Millipore, USA) prior to SPE. The sample was enriched by SPE (Supelco, USA) with the C18 cartridge that had been preconditioned with $10 \mathrm{~mL}$ of dichloromethane, $10 \mathrm{~mL}$ of methanol, and then $10 \mathrm{~mL}$ of ultrapure water. After enrichment, the cartridge was eluted with $10 \mathrm{~mL}$ of dichloromethane. The eluents were collected in a K-D concentrator and concentrated to approximately
$0.5 \mathrm{~mL}$ under a gentle nitrogen stream. Thereafter, $20 \mu \mathrm{L}$ of injection standards $(10 \mu \mathrm{g} / \mathrm{mL} \mathrm{HMB})$ were added, and the final volume was made up to $1 \mathrm{~mL}$ in dichloromethane for instrumental analysis.

2.3. Instrument Analysis. Samples were analyzed by using a GC2010 gas chromatograph coupled with a QP2010 mass spectrometer (GC-MS, Shimadzu, Japan). Aliquots of sample extracts $(1 \mu \mathrm{L})$ were introduced by the splitless injection at $280^{\circ} \mathrm{C}$. Chromatographic separation of PAHs was achieved on an Rtx-5MS capillary column (length $30.0 \mathrm{~m}$, i.d. $0.25 \mathrm{~mm}$, film $0.25 \mu \mathrm{m}$, Shimadzu, Japan) over $57 \mathrm{~min}$ using a triple ramp oven programme (initial temperature $60^{\circ} \mathrm{C} ; 20^{\circ} \mathrm{C} / \mathrm{min}$ to $160^{\circ} \mathrm{C} ; 3^{\circ} \mathrm{C} / \mathrm{min}$ to $280^{\circ} \mathrm{C}$, held for $6 \mathrm{~min}$; $20^{\circ} \mathrm{C} / \mathrm{min}$ to $300^{\circ} \mathrm{C}$, held for $\left.5 \mathrm{~min}\right)$. A constant flow $(1 \mathrm{~mL} /$ min) of ultrapure helium carrier gas (99.999\%) was maintained. Mass spectra were collected over the range $\mathrm{m} / z 50$ to 500. The temperatures of the transfer line and ion source were $220^{\circ} \mathrm{C}$ and $250^{\circ} \mathrm{C}$. Ionization of analyte was performed using the electron ionization at $70 \mathrm{eV}$. A full scan of the mixture standard containing each compound $(1 \mu \mathrm{g} / \mathrm{mL})$ allowed the identification of the compound peaks according to their retention times and mass spectra. Retention time locking with an internal standard was applied to ensure the reproducibility of retention time of each target compound. This was followed by data acquisition in the selective ion monitoring mode that entailed the identification of the most intense and distinct fragment ions for each compound, within a well-defined time window.

2.4. Quality Control and Assurance. Matrices-spiked control experiments were used to evaluate the method performance in parallel with each batch of samples. In brief, two liters of the contaminant-free ultrapure water were spiked with $10 \mu \mathrm{L}$ of the PAH mixture standards (each PAH congener at $10 \mu \mathrm{g} / \mathrm{mL}$ ), and the recovery rates of the 16 PAHs were $47 \%-116 \%(n=5)$. Procedure blanks were run with each batch of samples to evaluate possible contamination during analysis, and levels of PAHs were below the limit of quantification (LOQ) in all cases. The LOQs of PAHs were estimated as the concentration when the signal-to-noise ratio was $10: 1 \quad(\mathrm{~S} / \mathrm{N}=10)$. The method detection limit (MDL) was $0.049-5.57 \mathrm{ng} / \mathrm{L}$, assuming a final extract volume of $1.0 \mathrm{~mL}$ and surface water samples of $2 \mathrm{~L}$. Recovery rates were also evaluated by adding the $\mathrm{PAH}$ mixture standard (each PAH congener at $10 \mu \mathrm{g} / \mathrm{mL}$ ) into $2 \mathrm{~L}$ real surface water samples $(n=6)$ collected from Qinghe River in Beijing. The results showed that recovery rates of PAHs were $50 \%-104 \%$. The average recoveries of Phe-d10 and Chr-d12 were $114 \% \pm 4.5 \%$ and $71 \% \pm 3.8 \%$, respectively.

\subsection{Probabilistic Ecological Risk Assessment for PAH Mixture.} In this study, the probabilistic ecological risk assessment method was used to assess the hazard of PAHs to aquatic organisms in the Yellow River. Specifically, a joint probability curve (JPC) was generated through combining exposure and toxicity data [15]. The specific point on the JPC 


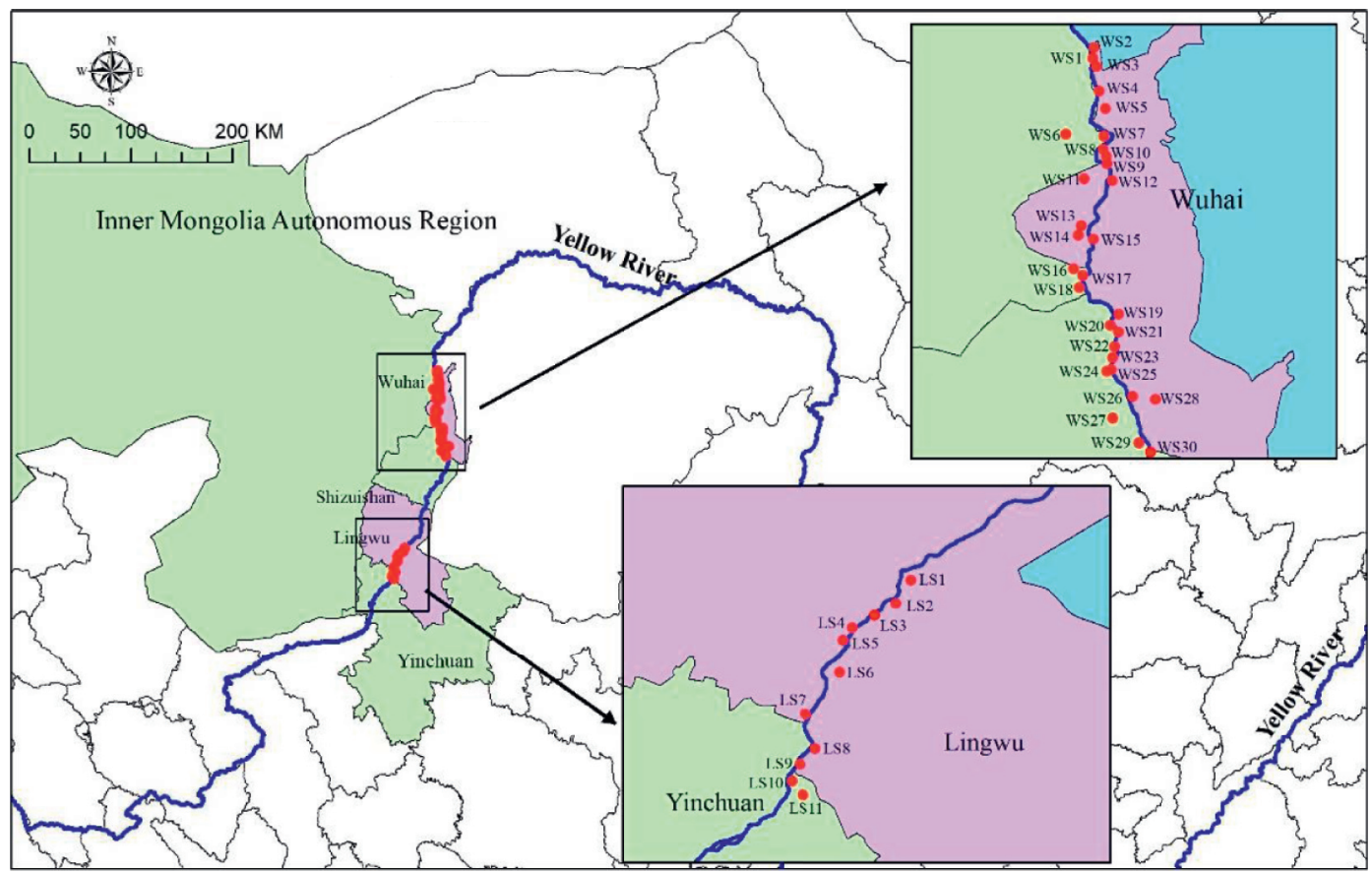

- Sites

— Yellow River

FIGURE 1: Schematic diagram showing the locations of the sampling sites in the Yellow River.

represents both the probability that the chosen fraction of species would be in danger, and the frequency with which the level of effect would be exceeded.

To reflect the additive effect of the 16 PAHs, BaP equivalency (BaPeq) of PAHs was calculated based on the toxic equivalency factors (TEFs) for PAHs [16]. Then, the ecological risk of PAH mixture was evaluated. Ecotoxicology data for $\mathrm{BaP}$ were collected from the United States Environmental Protection Agency ECOTOXicology Database (http://www.epa.gov/ecotox/). All toxicity data were the no observed effect concentration (NOEC) obtained from tests conducted in a freshwater system and the data selection procedure followed principles of accuracy, relevance, and reliability [17].

\section{Results and Discussion}

3.1. Concentrations and Distribution. Concentrations of the 16 PAHs in surface water from Wuhai and Lingwu sections of the Yellow River are presented in Figure 2. Total concentrations of PAHs ranged from $27.5 \mathrm{ng} / \mathrm{L}$ (WS16) to $233 \mathrm{ng} / \mathrm{L}$ (WS19) in the Wuhai section of the Yellow River with a mean concentration of $162 \mathrm{ng} / \mathrm{L}$, while PAH concentrations range from $135 \mathrm{ng} / \mathrm{L}$ (LS10) to $265 \mathrm{ng} / \mathrm{L}$ (LS6) in the Lingwu section with a mean concentration of $197 \mathrm{ng} / \mathrm{L}$. The concentration of Nap was the highest among different congeners, accounting for $12 \%$ and $14 \%$ of the total $\mathrm{PAH}$ concentrations on average for Wuhai and Lingwu sections, respectively. Average concentrations of most congeners in surface water from Lingwu section were slightly higher than that from Wuhai section, except for Phe, $\mathrm{BaA}, \mathrm{BkF}, \mathrm{DBA}$,

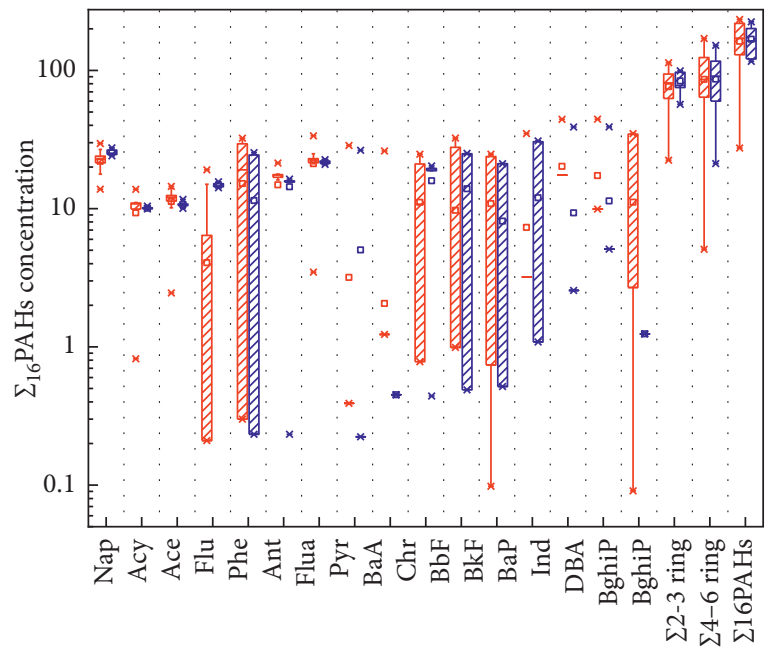

WII Yellow River (Wuhai section)

VIIA Yellow River (Lingwu section)

FIgURE 2: Concentrations of PAHs in surface water from Wuhai and Lingwu sections of the Yellow River.

and BghiP. In general, the compositional pattern of PAHs was in the following order for both studied areas: 3 rings $>4$ rings $>5$ rings $>2$ rings $>6$ rings (Figure 2).

We collected the available data on PAH concentrations in surface water surrounding coal mining areas from previously published literature. Through the comparison among different studies, it can be found that PAH concentrations in the present study were significantly lower than 
those in the Loskop Dam (South Africa, 1170-14500 ng/L) [9], surface water of rivers in the Shilong coalmine (China, 68-8377 ng/L) [13], and rivers in the Heshan coal district (China, 199-1351 ng/L) [5]. However, PAH concentrations in surface water of rivers in the Fengfeng coalmines (China, 1.35-2.92 ng/L) [12] were significantly lower than that in our study.

Table 1 shows a comparison of $\mathrm{PAH}$ concentrations in surface water samples collected from rivers around China during the past decade. When compared to other studies conducted in the Yellow River watershed, our results were in the same order of magnitude to that reported for PAHs in surface water collected from Henan reach [18] and Xi'an section [19] of the Yellow River but were significantly lower than that from the Yellow River Estuary [20]. A comparison was also made to studies conducted in regions other than the Yellow River watershed (Table 1). It can be found that the mean values of the total concentration of PAHs observed in the present study were comparable to that from the Songhua River [23], the Yangtze River Delta [26], the Poyang Lake [28], Xiamen Coastal Area [30], and the Chaohu Lake [32], slightly lower than that from the Daliao River Estuary [22], the Songhua River basin [21], and the Jiangsu section of the Yangtze River [25], but significantly lower than that from the Yangtze Estuary and coastal areas [29], the Liaohe River basin [21], the Taihu Lake [27], the Huaihe River basin [21], and the Weishan Lake [31]. Moreover, our results were significantly higher than that from the Baiyangdian Lake [24], the Fujiang River [23], the Pear River [33], the Dongjiang River [33], and the Pearl River Estuary [33, 34]. Overall, PAH concentrations in surface water collected from Wuhai and Lingwu sections of the Yellow River were at moderate levels in China.

\subsection{Source Apportionment}

3.2.1. Sources of PAHs in Wuhai Section of the Yellow River. Principal component analysis (PCA) was conducted to evaluate the contribution of different PAH sources, and the results are presented in Table 2, which shows the variable loadings describing the major contamination patterns and their explained variance. Note that Pyr, BaA, BaP, and Ind were not considered because of their low detection rates. Five principal components accounting for $81 \%$ of the total variance were extracted through PCA.

The first component (PC1) explained $38 \%$ of the total variance and was predominately loaded with Flua, Ace, Nap, Acy, and Ant. It has been reported that Flua and Ant were related to coal combustion-generated PAHs [2, 35-37]. Loadings of Acy and Nap have been associated with vaporization or spill of petroleum-related products [38]. Ace was one of the dominant PAHs from the coke industry and could enter into the Yellow River via industrial wastewater and atmospheric fallout [39]. Therefore, PC1 explained the compounds originating from coal combustion, spill of petroleum-related products, and the coke industry. The second component (PC2) contributed 15\% to the total variance and was heavily weighted with Flu and DBA. Flu was another one
TABle 1: Summary of concentrations (ng/L) of PAHs in surface water samples collected from rivers in China during the past decade.

\begin{tabular}{|c|c|c|c|c|c|}
\hline Locations & $n$ & Min & Max & Mean & References \\
\hline $\begin{array}{l}\text { Yellow River } \\
\text { (Wuhai section) }\end{array}$ & 30 & 27.5 & 234 & 162 & This study \\
\hline $\begin{array}{l}\text { Yellow River } \\
\text { (Lingwu section) }\end{array}$ & 11 & 135 & 265 & 197 & This study \\
\hline $\begin{array}{l}\text { Yellow River } \\
\text { (Henan reach) }\end{array}$ & 26 & 144 & 2361 & 662 & {$[18]$} \\
\hline $\begin{array}{l}\text { Yellow River } \\
\text { (Xi'an region) }\end{array}$ & 6 & 357 & 2017 & 824 & [19] \\
\hline $\begin{array}{l}\text { Yellow River Estuary } \\
\text { (flood season) }\end{array}$ & 8 & 474 & 1190 & 729 & {$[20]$} \\
\hline $\begin{array}{l}\text { Yellow River Estuary } \\
\text { (dry season) }\end{array}$ & 8 & 1682 & 6014 & 2944 & {$[20]$} \\
\hline Liaohe River Basin & 15 & 209 & 33930 & 4021 & {$[21]$} \\
\hline Daliao River Estuary & 12 & 139 & 1718 & 486 & {$[22]$} \\
\hline Songhua River & 7 & 88.6 & 140 & - & [23] \\
\hline Songhua River Basin & 15 & 7.12 & 9131 & 759 & {$[21]$} \\
\hline Baiyangdian Lake & 6 & 40.1 & 74 & 51 & {$[24]$} \\
\hline Fujiang River & 8 & 43.9 & 81 & - & [23] \\
\hline $\begin{array}{l}\text { Yangtze River } \\
\text { (Jiangsu section) }\end{array}$ & 15 & 12 & 3576 & 925 & {$[25]$} \\
\hline Yangtze River Delta & 14 & 12.9 & 638 & 201 & {$[26]$} \\
\hline Taihu Lake & 5 & 11000 & 34000 & - & [27] \\
\hline Poyang Lake & 40 & 5.56 & 266 & - & {$[28]$} \\
\hline $\begin{array}{l}\text { Yangtze Estuary and } \\
\text { coastal areas }\end{array}$ & 18 & 478 & 6273 & 1858 & [29] \\
\hline Xiamen coastal area & 13 & 62 & 342 & 151 & {$[30]$} \\
\hline Huaihe River Basin & - & 1700 & 7770 & 4386 & [21] \\
\hline Weishan Lake & 9 & 5350 & 12970 & 8572 & {$[31]$} \\
\hline Chaohu Lake & 15 & 95.6 & 370 & 171 & {$[32]$} \\
\hline Dongjiang River & 8 & 10.9 & 42.3 & 24.9 & [33] \\
\hline Pearl River & 8 & 15.4 & 48.1 & 27.1 & [33] \\
\hline Pearl River Estuary & 20 & 12.9 & 182 & 45.4 & {$[34]$} \\
\hline Pearl River Estuary & 3 & 11.7 & 18.6 & 15.1 & [33] \\
\hline
\end{tabular}

$n$, numbers of collected samples.

TABLE 2: Rotated component matrix of studied PAHs in the Yellow River (Wuhai section).

\begin{tabular}{lccccc}
\hline \multirow{2}{*}{ PAHs } & \multicolumn{5}{c}{ Components } \\
& 1 & 2 & 3 & 4 & 5 \\
\hline Nap & $\mathbf{0 . 9 1 2}$ & 0.195 & 0.014 & 0.158 & 0.086 \\
Acy & $\mathbf{0 . 8 8 4}$ & -0.156 & 0.093 & -0.168 & -0.032 \\
Ace & $\mathbf{0 . 9 2 1}$ & 0.038 & 0.184 & 0.198 & 0.148 \\
Flu & -0.055 & $\mathbf{0 . 8 6 1}$ & -0.004 & -0.073 & 0.042 \\
Phe & 0.154 & -0.336 & $\mathbf{0 . 5 8 9}$ & 0.158 & $\mathbf{0 . 4 1}$ \\
Ant & $\mathbf{0 . 6 2 3}$ & -0.038 & 0.5 & -0.057 & $\mathbf{0 . 4 0 8}$ \\
Flua & $\mathbf{0 . 9 0 7}$ & 0.105 & 0.187 & 0.122 & 0.225 \\
Chr & 0.173 & 0.086 & $\mathbf{0 . 8 5 5}$ & 0.128 & -0.21 \\
BbF & 0.248 & 0.059 & 0.296 & $\mathbf{0 . 7 2 9}$ & -0.155 \\
BkF & 0.229 & -0.047 & -0.077 & 0.002 & $\mathbf{0 . 9}$ \\
DBA & 0.154 & $\mathbf{0 . 7 8 1}$ & -0.025 & 0.004 & -0.12 \\
BghiP & -0.044 & -0.128 & -0.022 & $\mathbf{0 . 8 8 5}$ & 0.131 \\
Eigenvalues & 4.587 & 1.777 & 1.477 & 1.033 & 0.866 \\
\% variance & 38.226 & 14.809 & 12.309 & 8.606 & 7.216 \\
Cum. percentage & 38.226 & 53.035 & 65.344 & 73.95 & 81.166 \\
\hline
\end{tabular}

dominant PAHs from the coking process [39], while a relatively higher abundance of DBA has been identified as a marker of gasoline vehicle emissions. Hence, PC2 was 
reflective of PAHs from the coking process and vehicle exhausts. The third component (PC3) characterized for $12 \%$ of the total variance. This component was heavily loaded with Chr and Phe. Chr and Phe had been identified as typical tracers of coal combustion [36]. Hence, PC3 was reflective of PAHs derived from coal combustion. The fourth component (PC4) contributed $8.6 \%$ to the total variance and was dominated by BghiP and BbF. Dominance of BghiP and BbF over other PAHs has been attributed to diesel combustion $[40,41]$. Thus, PC4 was selected to represent diesel combustion source of PAHs in surface water of the Yellow River. The fifth component (PC5) was responsible for $7.2 \%$ of the total variance and weighted by BkF, Ant, and Phe. BkF has been identified as an indicator of diesel combustion [40,41], while it has been reported that Ant and Phe were related to coal combustion [2, 36, 42]. Hence, PC5 was reflective of PAHs from coal and diesel combustion.

Using the multivariate linear regression (MLR) from PCA factor scores, the equation was calculated as follows:

$$
\begin{aligned}
\sum_{16} \mathrm{PAHs}= & 0.901 \times \mathrm{PC} 1+0.408 \times \mathrm{PC} 2+0.454 \times \mathrm{PC} 3 \\
& +0.457 \times \mathrm{PC} 4+0.529 \times \mathrm{PC} 5\left(R^{2}=0.6\right) .
\end{aligned}
$$

Therefore, PAHs in Wuhai section of the Yellow River were originated from four major sources, and the quantitative contributions were $35 \%$ from coal combustion, $34 \%$ from vehicle exhausts, $21 \%$ from coke industry, and $11 \%$ from spill of petroleum-related products.

3.2.2. Sources of PAHs in Lingwu Section of the Yellow River. Note that BaA, BghiP, Pyr, Ind, and DBA were not considered in the PCA because of their low detection rates. According to the results presented in Table 3, PAHs were separated into four major categories. Over $85 \%$ of the total variance of the data could be interpreted by four eigenvectors.

The first component (PC1) explained $38 \%$ of the total variance and was predominately loaded with Acy, Ace, and Flu. It has been reported that Ace and Flu were related to coke industry [39], while Acy has been related to vaporization or spill of petroleum-related products [38]. Therefore, $\mathrm{PC} 1$ explained the compounds originating from coking industry and spill of petroleum-related products. The second component (PC2) contributed $24 \%$ to the total variance and was heavily weighted with $\mathrm{BbF}$ and Flua. BbF has been recognized as an indicator of diesel combustion [40, 41], while Flua has been linked to coal combustion [2, 35-37]. Hence, PC2 was a reflection of PAHs from diesel exhaust and coal combustion. The third component (PC3) contributed $15 \%$ to the total variance and was dominated by $\mathrm{Chr}$ and Ant. Coal combustion could be sources of Chr and Ant [36]. Thus, PC3 was selected to represent coal combustion originated PAHs. The fourth component (PC4) was responsible for $11 \%$ of total variance and weighted by $\mathrm{BkF}$ and $\mathrm{NaP}$. It has been pointed out that a relatively higher
TABLE 3: Rotated component matrix of studied PAHs in the Yellow River (Lingwu section).

\begin{tabular}{lcccc}
\hline \multirow{2}{*}{ PAHs } & \multicolumn{4}{c}{ Components } \\
& 1 & 2 & 3 & 4 \\
\hline Nap & 0.521 & -0.417 & 0.294 & $\mathbf{0 . 6 2 3}$ \\
Acy & $\mathbf{0 . 9 5 3}$ & 0.038 & 0.036 & 0.234 \\
Ace & $\mathbf{0 . 9 0 4}$ & -0.026 & 0.295 & -0.144 \\
Flu & $\mathbf{0 . 9 2}$ & 0.193 & 0.23 & -0.038 \\
Phe & -0.436 & -0.786 & 0.191 & -0.176 \\
Ant & 0.309 & -0.247 & $\mathbf{0 . 8 3 7}$ & -0.222 \\
Flua & 0.326 & $\mathbf{0 . 7 5 3}$ & 0.389 & 0.024 \\
Chr & 0.275 & 0.101 & $\mathbf{0 . 8 2 9}$ & -0.031 \\
BbF & -0.206 & $\mathbf{0 . 9 1 6}$ & -0.019 & 0.046 \\
BkF & -0.036 & 0.257 & -0.166 & $\mathbf{0 . 9 2 6}$ \\
BaP & -0.168 & 0.455 & 0.599 & 0.298 \\
Eigenvalues & 4.127 & 2.623 & 1.67 & 1.232 \\
\% variance & 37.521 & 23.841 & 15.186 & 11.202 \\
Cum. percentage & 37.521 & 61.362 & 76.548 & 87.75 \\
\hline
\end{tabular}

abundance of BkF was the marker of diesel vehicle emission $[40,41]$. In the meantime, Nap was associated with vaporization or spill of petroleum-related products [38]. Hence, PC4 was representative of PAHs from petroleumrelated products and diesel combustion.

PCA-MLR was performed, and the following equation was established:

$$
\begin{aligned}
\sum_{16} \mathrm{PAHs}= & 0.175 \times \mathrm{PC} 1+0.043 \times \mathrm{PC} 2+0.417 \times \mathrm{PC} 3 \\
& +0.230 \times \mathrm{PC} 4\left(R^{2}=0.4\right) .
\end{aligned}
$$

Therefore, PAHs in Lingwu section of the Yellow River were originated from four major sources and the quantitative contributions were $34 \%$ from coal combustion, $27 \%$ from spill of petroleum-related products, $24 \%$ from coke industry, and $16 \%$ from vehicle exhausts.

It should be noted that the quantitative results for source contributions should be explained with caution due to the small $R^{2}$ value of the regression, which could be caused by the limited number of data points used in the source identification. The other reasons could be the complex sources of PAHs in Lingwu section of the Yellow River, as it is well known that Lingwu was close to Yinchuan, and as well, it is one of the most important bases of coal chemical industry in the Northwestern China. More data should be collected for further analysis.

3.3. Ecological Risk Assessment. $\mathrm{BaP}_{\mathrm{eq}} \mathrm{s}$ of $\mathrm{PAHs}$ ranged from $0.06 \mathrm{ng} / \mathrm{L}$ to $264 \mathrm{ng} / \mathrm{L}$ in surface water in Wuhai section of the Yellow River. As for Lingwu section, $\mathrm{BaP}_{\text {eq }} \mathrm{s}$ of PAHs ranged from $0.59 \mathrm{ng} / \mathrm{L}$ to $257 \mathrm{ng} / \mathrm{L}$ among different sampling sites, which was similar to that in surface water of Wuhai section. As shown in Figure 3, probabilities of exceeding the NOEC for $5 \%$ of the species were $28 \%$ and $32 \%$ for PAHs in surface water in Wuhai and Lingwu sections of the Yellow River, respectively. This indicates that ecological risks of PAHs to aquatic organisms were high in both study areas. It 


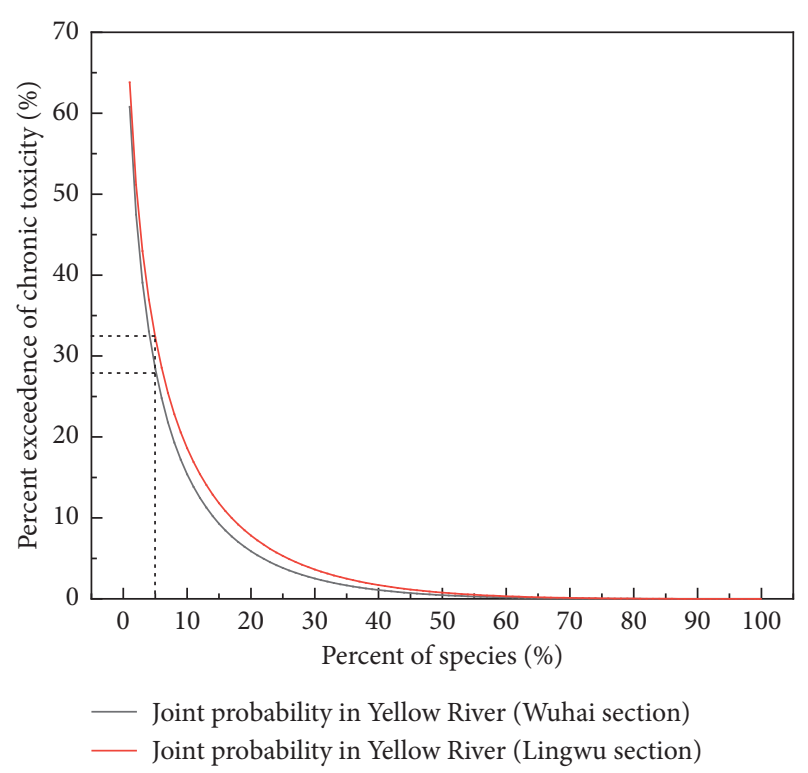

FIgURE 3: JPC of PAHs in surface water of the Yellow River.

has been demonstrated that there is an urgent need for taking measures to reduce the ecological risk of PAHs in the aquatic environment in the study areas.

However, there could be some uncertainties in the above assessing results. Other concomitants that were not taken into account may cause additive and synergistic effects, which could cause the underestimation of toxic effects [43]. For example, Wang et al. [44] reported that the joint toxic effect was observed when exposing the marine microalga to the mixture of Ant with profenofos. Moreover, the bioaccumulation and metabolism of PAHs in aquatic organisms were not being considered. In addition, collected toxic data and exposure data were limited. As emission continues, concentrations of PAHs in the aquatic ecosystem could increase.

\section{Conclusions}

The results showed that total PAH concentrations varied from $27.5 \mathrm{ng} / \mathrm{L}$ to $234 \mathrm{ng} / \mathrm{L}$ and $135 \mathrm{ng} / \mathrm{L}$ to $265 \mathrm{ng} / \mathrm{L}$ in surface water of Wuhai and Lingwu sections, respectively. PAHs in Wuhai section of the Yellow River were mainly from coal combustion (35\%) and vehicle exhausts (34\%). Results of ERA showed that the probabilities of exceeding the chronic toxicity for $5 \%$ of the species were $28 \%$ and $32 \%$ for PAHs in surface water from Wuhai and Lingwu sections, respectively. It has been demonstrated that there is an urgent need for taking measures to reduce the ecological risk of PAHs in the aquatic environment in our study areas.

\section{Data Availability}

The numerical data used to support the findings of this study are included within the article.

\section{Conflicts of Interest}

The authors declare that they have no conflicts of interest.

\section{Acknowledgments}

This work was cosupported by the National Key R\&D Program of China (2017YFC0504401), National Natural Science Foundation of China (21777188), and Fundamental Research Funds for the Central Universities in China (2015QH02). Q.B. is also funded by Yue Qi Young Scholar Project, China University of Mining \& Technology, Beijing (2017QN15). The authors thank Mingyue Zou, Xiaoyan $\mathrm{Zhu}$, and Yali Guo for their assistance during the sample pretreatment, and Su Meng and Jihong Wu for their assistance during the instrumental analysis.

\section{References}

[1] Y. Yang, X.-X. Zhang, and T. Korenaga, "Distribution of polynuclear aromatic hydrocarbons (PAHs) in the soil of Tokushima, Japan," Water, Air, and Soil Pollution, vol. 138, no. 1-4, pp. 51-60, 2002.

[2] M. Yunker, R. Macdonald, D. Goyette et al., "Natural and anthropogenic inputs of hydrocarbons to the Strait of Georgia," The Science of The Total Environment, vol. 225, no. 3, pp. 181-209, 1999.

[3] M. B. Yunker, R. W. Macdonald, R. Vingarzan, R. H. Mitchell, D. Goyette, and S. Sylvestre, "PAHs in the Fraser River basin: a critical appraisal of PAH ratios as indicators of PAH source and composition," Organic Geochemistry, vol. 33, no. 4, pp. 489-515, 2002.

[4] D. Chen, Q. Feng, H. Liang, B. Gao, and E. Alam, "Distribution characteristics and ecological risk assessment of polycyclic aromatic hydrocarbons (PAHs) in underground coal mining environment of Xuzhou," Human and Ecological Risk Assessment: An International Journal, vol. 25, no. 6, pp. 1564-1578, 2019.

[5] H.-F. Huang, X.-L. Xing, Z.-Z. Zhang et al., "Polycyclic aromatic hydrocarbons (PAHs) in multimedia environment of Heshan coal district, Guangxi: distribution, source diagnosis and health risk assessment," Environmental Geochemistry and Health, vol. 38, no. 5, pp. 1169-1181, 2016.

[6] Z. Ouyang, L. Gao, X. Chen, S. Yao, and S. Deng, "Distribution, source apportionment and ecological risk assessment of polycyclic aromatic hydrocarbons in the surface sediments of coal mining subsidence waters," RSC Advances, vol. 6, no. 75, pp. 71441-71449, 2016.

[7] B. Gao, Q. Feng, L. Zhou, H. Wu, and E. Alam, "Distributions of polycyclic aromatic hydrocarbons in coal in China," Polish Journal of Environmental Studies, vol. 28, no. 3, pp. 16651674, 2019.

[8] R. Wang, G. Liu, C.-L. Chou, J. Liu, and J. Zhang, "Environmental assessment of PAHs in soils around the Anhui coal district, China," Archives of Environmental Contamination and Toxicology, vol. 59, no. 1, pp. 62-70, 2010.

[9] M. P. Seopela, R. I. McCrindle, S. Combrinck, and T. J.-C. Regnier, "Hazard assessment of polycyclic aromatic hydrocarbons in water and sediment in the vicinity of coalmines," Journal of Soils and Sediments, vol. 16, no. 12, pp. 2740-2752, 2016.

[10] M. Hendryx, K. O’Donnell, and K. Horn, "Lung cancer mortality is elevated in coal-mining areas of Appalachia," Lung Cancer, vol. 62, no. 1, pp. 1-7, 2008.

[11] F. Goodarzi and P. K. Mukhopadhyay, "Metals and polyaromatic hydrocarbons in the drinking water of the Sydney basin, Nova Scotia, Canada: a preliminary assessment of their 
source," International Journal of Coal Geology, vol. 43, no. 1-4, pp. 357-372, 2000.

[12] C. Hao, Y. Huang, D. Ma et al., "Environmental behaviors of PAHs in ordovician limestone water of Fengfeng coal mining area in China," Environmental Monitoring and Assessment, vol. 190, no. 12, p. 701, 2018.

[13] C. Yang, N. Zhong, D. Chen, J. Wang, and X. Peng, "Composition and distribution characteristics of polycyclic aromatic hydrocarbons in water samples from a coal-mining area, Henan, China," Journal of Safety and Environment, vol. 7, no. 1, pp. 75-78, 2007, in Chinese.

[14] Q. Bu, D. Wang, Z. Wang, J. Gu, and N. Cao, "Removal analysis on polycyclic aromatic hydrocarbons and halogenated alkanes by water processing," Water \& Wastewater Engineering, vol. 37, no. 11, pp. 9-15, 2011, in Chinese.

[15] K. Solomon, J. Giesy, and P. Jones, "Probabilistic risk assessment of agrochemicals in the environment," Crop Protection, vol. 19, no. 8-10, pp. 649-655, 2000.

[16] I. C. T. Nisbet and P. K. LaGoy, "Toxic equivalency factors (TEFs) for polycyclic aromatic hydrocarbons (PAHs)," Regulatory Toxicology and Pharmacology, vol. 16, no. 3, pp. 290-300, 1992.

[17] H.-J. Klimisch, M. Andreae, and U. Tillmann, "A systematic approach for evaluating the quality of experimental toxicological and ecotoxicological data," Regulatory Toxicology and Pharmacology, vol. 25, no. 1, pp. 1-5, 1997.

[18] J.-H. Sun, G.-L. Wang, Y. Chai, G. Zhang, J. Li, and J. Feng, "Distribution of polycyclic aromatic hydrocarbons (PAHs) in Henan reach of the Yellow River, Middle China," Ecotoxicology and Environmental Safety, vol. 72, no. 5, pp. 16141624, 2009.

[19] W. Wang, J. Zhang, X. Li et al., "Characteristics and sources of polycyclic aromatic hydrocarbons pollution in water of Xi'an outskirt regions," Agricultural Research in the Arid Areas, vol. 33, no. 5, pp. 201-206, 2015, in Chinese.

[20] Y. Lang, Y. Jia, Z. Liu, Z. Gao, and X. Wang, "Seasonal distribution characteristics and sources of polycyclic aromatic hydrocarbons (PAHs) in water samples from the Yellow River estuary," Periodical of Ocean University of China, vol. 38, no. 4, pp. 640-646, 2008, in Chinese.

[21] G. Guo, F. Wu, H. He, R. Zhang, H. Li, and C. Feng, "Distribution characteristics and ecological risk assessment of PAHs in surface waters of China," Science China Earth Sciences, vol. 55, no. 6, pp. 914-925, 2012.

[22] B. Men, M. He, L. Tan, C. Lin, and X. Quan, "Distributions of polycyclic aromatic hydrocarbons in the Daliao River estuary of Liaodong Bay, Bohai sea (China)," Marine Pollution Bulletin, vol. 58, no. 6, pp. 818-826, 2009.

[23] C. Wang, Z. Yang, X. Xia, H. Cheng, and T. Yu, "Distribution and sources of PAHs in typical Chinese rivers," Geoscience, vol. 26, no. 2, pp. 400-406, 2012, in Chinese.

[24] Y. Zhu, W. Wu, J. Wang et al., "Distribution, sources and ecological risks of polycyclic aromatic hydrocarbons in watersediment system in lake small Baiyangdian," Journal of Lake Sciences, vol. 21, no. 5, pp. 637-646, 2009, in Chinese.

[25] H. He, G.-J. Hu, C. Sun et al., "Trace analysis of persistent toxic substances in the main stream of Jiangsu section of the Yangtze River, China," Environmental Science and Pollution Research, vol. 18, no. 4, pp. 638-648, 2011.

[26] L. Zhang, L. Dong, L. Ren et al., "Concentration and source identification of polycyclic aromatic hydrocarbons and phthalic acid esters in the surface water of the Yangtze River Delta, China," Journal of Environmental Sciences, vol. 24, no. 2, pp. 335-342, 2012.
[27] J.-X. Guo and J. Fang, "The distribution of n-alkanes and polycyclic aromatic hydrocarbons in water of Taihu Lake," Procedia Environmental Sciences, vol. 12, pp. 258-264, 2012.

[28] H. Zhi, Z. Zhao, and L. Zhang, "The fate of polycyclic aromatic hydrocarbons (PAHs) and organochlorine pesticides (OCPs) in water from Poyang Lake, the largest freshwater lake in China," Chemosphere, vol. 119, pp. 1134-1140, 2015.

[29] D.-N. Ou, M. Liu, S.-Y. Xu et al., "Distribution and ecological risk assessment of polycyclic aromatic hydrocarbons in overlying waters and surface sediments from the Yangtze estuarine and coastal areas," Environmental Science, vol. 30, no. 10, pp. 3043-3049, 2009, in Chinese.

[30] M.-L. Ya, X.-H. Wang, Y.-L. Wu, C.-X. Ye, and Y.-Y. Li, "Enrichment and partitioning of polycyclic aromatic hydrocarbons in the sea surface microlayer and subsurface water along the coast of Xiamen Island, China," Marine Pollution Bulletin, vol. 78, no. 1-2, pp. 110-117, 2014.

[31] X. Zheng, B. Han, H. Jiang, and K. Liu, "Distribution and source of polycyclic aromatic hydrocarbons in the water of aquatic product cage culture area of Weishan Lake," Sichuan Environment, vol. 29, no. 6, pp. 21-24, 2010, in Chinese.

[32] N. Qin, W. He, Y. Wang et al., "Residues and health risk of polycyclic aromatic hydrocarbons in the water and aquatic products from Lake Chaohu," Acta Scientiae Circumstantiae, vol. 33, no. 1, pp. 230-239, 2013, in Chinese.

[33] H. Li, L. Lu, W. Huang, J. Yang, and Y. Ran, "In-situ partitioning and bioconcentration of polycyclic aromatic hydrocarbons among water, suspended particulate matter, and fish in the Dongjiang and Pearl Rivers and the Pearl River Estuary, China," Marine Pollution Bulletin, vol. 83, no. 1, pp. 306-316, 2014.

[34] X.-J. Luo, B.-X. Mai, Q.-S. Yang, S.-J. Chen, and E. Y. Zeng, "Distribution and partition of polycyclic aromatic hydrocarbon in surface water of the Pearl River Estuary, South China," Environmental Monitoring and Assessment, vol. 145, no. 1-3, pp. 427-436, 2008.

[35] Y. Liu, L. Chen, Q.-H. Huang, W.-Y. Li, Y.-J. Tang, and J.-F. Zhao, "Source apportionment of polycyclic aromatic hydrocarbons (PAHs) in surface sediments of the Huangpu River, Shanghai, China," Science of the Total Environment, vol. 407, no. 8, pp. 2931-2938, 2009.

[36] P. Masclet, G. Mouvier, and K. Nikolaou, "Relative decay index and sources of polycyclic aromatic hydrocarbons," Atmospheric Environment (1967), vol. 20, no. 3, pp. 439-446, 1986.

[37] C. Biache, L. Mansuy-Huault, and P. Faure, "Impact of oxidation and biodegradation on the most commonly used polycyclic aromatic hydrocarbon $(\mathrm{PAH})$ diagnostic ratios: implications for the source identifications," Journal of Hazardous Materials, vol. 267, pp. 31-39, 2014.

[38] M. P. Zakaria, H. Takada, S. Tsutsumi et al., "Distribution of polycyclic aromatic hydrocarbons (PAHs) in rivers and estuaries in Malaysia: a widespread input of petrogenic PAHs," Environmental Science \& Technology, vol. 36, no. 9, pp. 1907-1918, 2002.

[39] M. F. Simcik, S. J. Eisenreich, and P. J. Lioy, "Source apportionment and source/sink relationships of PAHs in the coastal atmosphere of Chicago and Lake Michigan," Atmospheric Environment, vol. 33, no. 30, pp. 5071-5079, 1999.

[40] C. K. Li and R. M. Kamens, "The use of polycyclic aromatic hydrocarbons as source signatures in receptor modeling," Atmospheric Environment. Part A. General Topics, vol. 27, no. 4, pp. 523-532, 1993. 
[41] A. Motelay-Massei, D. Ollivon, B. Garban, K. TiphagneLarcher, I. Zimmerlin, and M. Chevreuil, "PAHs in the bulk atmospheric deposition of the Seine river basin: source identification and apportionment by ratios, multivariate statistical techniques and scanning electron microscopy," Chemosphere, vol. 67, no. 2, pp. 312-321, 2007.

[42] F. Tian, J. Chen, X. Qiao et al., "Sources and seasonal variation of atmospheric polycyclic aromatic hydrocarbons in Dalian, China: factor analysis with non-negative constraints combined with local source fingerprints," Atmospheric Environment, vol. 43, no. 17, pp. 2747-2753, 2009.

[43] B. Wang, G. Yu, J. Huang, Y. Yu, H. Hu, and L. Wang, “Tiered aquatic ecological risk assessment of organochlorine pesticides and their mixture in Jiangsu reach of Huaihe River, China," Environmental Monitoring and Assessment, vol. 157, no. $1-4$, pp. 29-42, 2009

[44] Y. Wang, X. X. Tang, and Y. Q. Li, “The joint toxic effect of anthracene and profenofos on marine microalga," Experiment \& Technique, vol. 24, no. 4, pp. 5-7, 2000, in Chinese. 